\title{
A response duration technique for measuring stimulus generalization
}

Eight male albino rats were given six 1-hr. training sessions on a simple light, no-light operant discrimination. During the following six sessions the intensity of the $S \Delta$ stimulus was systematically varied and the response duration of the first response in an $S^{\Delta}$ trial was measured. It was found that response duration was linearly related to the intensity of the test $S^{\Lambda}$

A previous study (Kellicutt, 1966) showed that discriminative stimuli gain control over the duration of responses in an operant discrimination. Basically, the study demonstrated that when reward occurred upon the completion of a response, the first response in an $\mathrm{S}^{\mathrm{D}}$ or $\mathrm{S}^{\Delta}$ trial provided a reliable index of discriminative behavior. Thus, the duration of the first response in an $\mathrm{S}^{\mathrm{D}}$ trial was characteristically short and quite uniform. On the other hand, first responses in an $s^{\Delta}$ trial were characteristically quite variable and long in duration. The purpose of the present study was to determine whether response duration could be used as a measure of stimulus generalization in the kind of probe generalization technique employed by Pierre1 \& Sherman(1962). Method

The apparatus employed has been described in detail elsewhere (Kellicutt, 1966). Basically, it consisted of a Skinner box designed to restrict the animal's responses to a single limb (right forepaw). The operandum was a plunger mounted at floor level which could be pulled a maximum of 1.5 in. Any movement of the plunger which lasted longer than $5 \mathrm{msec}$. (excursion greater than $3 / 16$ in.) was recorded. Rewards $(.01 \mathrm{ml}$ of water/reinforcement), when delivered, occurred only on release of the operandum and hence, no reward cues were available during the execution of the response. Eight male albino rats were placed on a $23 \mathrm{hr} ., 50 \mathrm{~min}$. water deprivation schedule. After three days on this regimen each was placed in the apparatus and the plunger pull response was shaped through a method of successive approximations. On the session following acquisition, discrimination training was begun. A discrimination session consisted of $301-\min$. periods of $\mathrm{SD}$ alternated with $301-\mathrm{min}$. periods of $\mathrm{s}^{\Delta}$. The $\mathrm{S}^{\Delta}$ stimulus consisted of illumination of a 2-in. diameter translucent screen located in the front of the cage above the reward site. Illumination was provided by a modified In-line digital display unit. During training the $\mathrm{S}^{\Delta}$ intensity consisted of illumination by three $6.3 \mathrm{\nabla}$ bulbs of the In-line display behind the screen. During $s^{\Delta}$, of course, no response was rewarded. $\mathrm{SD}$ consisted of no-light on the screen and water reinforcements for all responses. During discrimination training the num- ber of responses in $\mathrm{S}^{D}$ and $\mathrm{s}^{\Delta}$, as well as the total duration of all responses made during these periods, were recorded. The following six 1-hr. sessions were generalization test sessions. The stimulus present during the first six $\mathrm{s}^{\Delta}$ trials was the same as the training stimulus (three lights on the screen). The following six nonreinforced trials were generalization test trials. During these trials six generalization stimuli were randomly presented. They consisted of no-light on the screen (an $\mathrm{S}^{\mathrm{D}}$ stimulus in the temporal position of the $S^{\Delta}$ ) one light, two lights, three lights ( $S^{\Delta}$ training stimulus) four lights, or five lights. During these trials the duration of the first response as well as the total duration of the succeeding responses in that trial were measured. During the remaining $36 \mathrm{~min}$. of the session the $S^{\Delta}$ stimulus was three lights and was alternated with $\mathrm{S}^{\mathrm{D}}$ trials.

\section{Resulis and Discussion}

Upon the completion of discrimination training the average response rate in the presence of $S^{D}$ was 12.9 responses per minute as opposed to 3.2 responses per minute for the $S^{\Delta}$ trials. Average duration during an $S^{D}$ trial on the sixth session of discrimination training was $.58 \mathrm{sec}$. Average response duration during an $\mathrm{s}^{\Delta}$ trial was $1.32 \mathrm{sec}$. The first response durations for the 0 -light condition were not considered in the analyses since they were, as expected, quite $\mathrm{S}^{\mathrm{D}}$-like (mean .47 sec.). Their inclusion would in all likelihood inflate $\mathbf{F}$ ratios and leave unanswered the question of whether the duration technique could discriminate between response tendencies to stimuli varying with in a particular reward condition.

The results for response rate under the generalization test conditions are shown in Fig. 1. These results

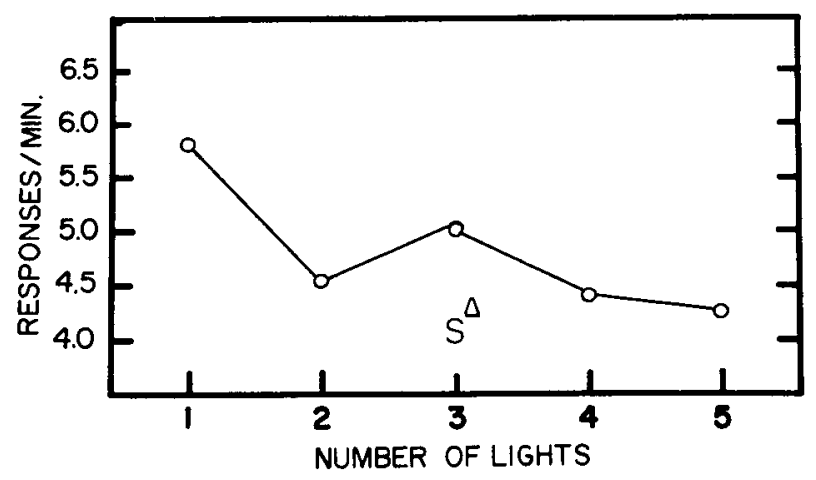

Fig. 1. Mean response rate in responses per minute in the presence of the five generalization test lights across the six test sessions. 


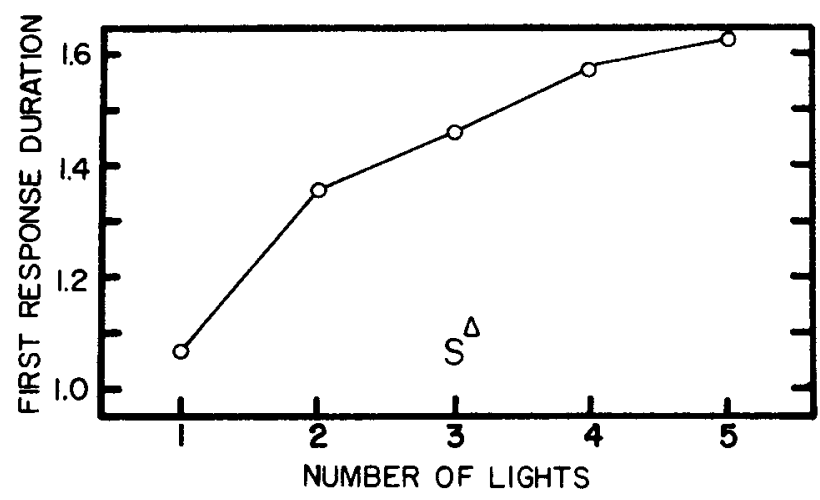

Fig. 2. Mean duration of the first response in a generalization test trial in the presence of the five generalization test lights across the six generalization test sessions.

are in accord with those obtained by Pierrel \& Sherman (1962). A trend analysis performed on these data show a significant linear trend $(F=4.85, \mathrm{df}=1 / 28, \mathrm{p}<.05)$; the more intense the $S^{\Delta}$, the lower the rate of response. The results for the duration of the first response across generalization stimuli are presented in Fig. 2. Here, once again, a trend analysis revealed a significant linear component $(F=7.89, \mathrm{df}=1 / 28, p<.025)$. Analysis of the mean durations for all responses in a generalization test trial across generalization conditions revealed no significant differences $(F<1)$.

The major advantage of this technique over others used to measure stimulus generalization about a nonreinforced stimulus (Schwartzbaum \& Kellicutt, 1963; Sherman \& Pierrel, 1962) should be obvious. The technique minimizes the opportunity for new learning to occur in the presence of the generalization stimuli since generalization test trials need only be long enough to allow one response to occur. This is of particular importance when measuring $S^{\Delta}$ generalization because of the characteristically low rate of response that one expects in the presence of the stimuli, necessitating lengthy test periods to obtain reliable measurements.

The present results are in accord with an application of Amsel's (1962) theory of frustrative nonreward to operant discrimination learming situations proposed by Kellicutt (1966). Briefly, variable, long duration $\mathrm{S}^{\Delta}$ responses are to be viewed as "primitive" competing behaviors which become conditioned to the $\mathrm{S}^{\Delta}$ stimuli. They are to be thought of as qualitatively, rather than quantitatively different from the $\mathrm{S}^{\mathrm{D}}$ response. One would expect, that if the various competing responses that could occur during $\mathrm{S}^{\Delta}$ had different thresholds of elicitation, the probability of the learned response should vary inversely with the intensity of $S^{\Delta}$. The more varied the behaviors during $S^{\Delta}$, the greater the likelihood of measuring an operant both qualitatively and quantitatively different from those measured under $\mathrm{S}^{\mathrm{D}}$, e.g., long duration responses.

\section{References}

Amsel, A. Frustrative nonreward in partial reinforcement and discrimination learning; some recent history and a theoretical extension. Psychol. Rev., 1962, 69, 306-328.

Kellicutt, M.H. Response duration during an operant discrimination. J. exp. Psychol., 1966, in press.

Pierrel, Rosemary, \& Sherman, J. G. Generalization and discrimination as a function of the SD-S delta intensity difference. J. exp. Anal. Behav., 1962, 5, 67-71.

Schwartzbaum, J. S., \& Kellicutt, M. H. Inverted generalization gradients about a nonreinforced stimulus. Psychol. Rep., 1962, 11, 791-792. 